\title{
Gene-specific vulnerability to imprinting variability in human embryonic stem cell lines
}

\author{
Kee-Pyo Kim, ${ }^{1}$ Alexandra Thurston, ${ }^{1}$ Christine Mummery, ${ }^{2}$ Dorien Ward-van \\ Oostwaard, ${ }^{2}$ Helen Priddle, ${ }^{1}$ Cinzia Allegrucci, ${ }^{1}$ Chris Denning, ${ }^{1}$ and Lorraine Young ${ }^{1,3}$ \\ ${ }^{1}$ Wolfson Centre for Stem Cells, Tissue Engineering and Modelling (STEM), University of Nottingham, Centre for Biomolecular \\ Sciences, Nottingham NG7 2RD, United Kingdom; ${ }^{2}$ Hubrecht Laboratory, Netherlands Institute for Developmental Biology \\ and the Interuniversity Cardiology Institute of the Netherlands, 3584 CT Utrecht, The Netherlands
}

\begin{abstract}
Disregulation of imprinted genes can be associated with tumorigenesis and altered cell differentiation capacity and so could provide adverse outcomes for stem cell applications. Although the maintenance of mouse and primate embryonic stem cells in a pluripotent state has been reported to disrupt the monoallelic expression of several imprinted genes, available data have suggested relatively higher imprint stability in the human equivalents. Identification of 202 heterozygous loci allowed us to examine the allelic expression of 22 imprinted genes in 22 human embryonic stem cell lines. Half of the genes examined (IPW, H19, MEG3, MEST isoforms 1 and 2, PEG10, MESTIT1, NESP55, ATP1OA, PHLDA2, IGF2) showed variable allelic expression between lines, indicating vulnerability to disrupted imprinting. However, seven genes showed consistent monoallelic expression (NDN, MAGEL2, SNRPN, PEG3, KCNQ1, $K C N Q 1 O T 1$, CDKN1C). Furthermore, four genes known to be monoallelic or to exhibit polymorphic imprinting in later-developing human tissues (TP73, IGF2R, WT1, SLC22A18) were always biallelic in hESCs. MEST isoform 1, PEG10, and NESP55 showed an association between the variability observed in interline allelic expression status and the DNA methylation of previously identified regulatory regions. Our results demonstrate gene-specific differences in the stability of imprinted loci in human embryonic stem cells and identify disrupted DNA methylation as one potential mechanism. We conclude the prudence of including comprehensive imprinting analysis in the continued characterization of human embryonic stem cell lines.
\end{abstract}

[Supplemental material is available online at www.genome.org.]

Genomic imprinting describes the parent of origin-specific monoallelic expression of a subset of genes that arises as a result of differential epigenetic/chromatin modifications during gametogenesis and preimplantation development (Ferguson-Smith and Surani 2001; Morison et al. 2005). Post-fertilization, the sperm and egg epigenomes are actively reprogrammed into a functional embryonic nucleus with major remodeling of chromatin, histone modifications, and DNA methylation (Jaenisch and Bird 2003; Morgan et al. 2005). Epigenetic disruption to imprinted genes has been described in the preimplantation embryos of a range of species when assisted reproduction technologies have been applied (Young et al. 2001; Mann et al. 2003, 2004; Maher 2005; Fujimoto et al. 2006; Sato et al. 2007). Thus we have previously reasoned that at least some human embryonic stem cells (hESCs), derived from human embryos cultured in vitro to the blastocyst stage, may also stably inherit imprinting errors from the donor embryo. It is also possible that hESC lines derived from normal embryos inherit unstable imprints during in vitro stem cell culture (Allegrucci et al. 2004). Preliminary studies of a limited number of imprinted genes in six embryonic stem cell lines detected little variation in the allelic expression status of imprinted genes (Rugg-Gunn et al. 2005; Sun et al. 2006), although a recent study of 10 genes in three to 24 informative lines suggests that loss of imprinting can be more readily detected by increasing the number of lines analyzed (Adewumi et al. 2007). Thus we wished to further investigate stability of a wider range of imprinted genes (22) in 22 stem cell lines and also

${ }^{3}$ Corresponding author.

E-mail Lorraine.Young@nottingham.ac.uk; fax 44(0)115-823-1230. Article published online before print. Article and publication date are at http:// www.genome.org/cgi/doi/10.1101/gr.6609207. to provide mechanistic insight into imprinting instability by assaying DNA methylation. Since different cell cycle, senescence, spontaneous transformation, and tumorigenic potential characteristics were found in mouse fetal fibroblasts with either two female (parthenogenetic) or two male (androgenetic) genomes (Hernandez et al. 2003), the possibility that disrupted maternal and paternal imprints could confer different phenotypes on human embryonic stem cells requires careful investigation. Furthermore, imprinting can occur in a tissue-specific and developmental stage-specific manner. However, for most genes identified as imprinted in the human (Morison et al. 2005), the allelic expression status neither in the human blastocyst nor in human embryonic stem cells is known.

Although both histone modifications and DNA methylation now have well-established roles in contributing to the allelespecific gene expression at imprinted loci (Lewis et al. 2004; Umlauf et al. 2004), the ontogeny of adding and completing these modifications to provide fully established, stable imprints is not well understood, particularly in the preimplantation stages. Recent evidence has suggested that human fetal tissues may utilize DNA methylation at imprinted loci, whereas the equivalent genes in the placenta rely less on this long-term silencing mechanism, perhaps enhancing the plasticity of placental imprints and allowing them to adapt more readily to alterations in, for example, maternal nutrition (Monk et al. 2006). Relative to cancer cell lines, the mean methylation of seven imprinted genes was relatively invariant between human embryonic stem cell lines (Bibikova et al. 2006). Additionally, in the BG01V line, the SNRPN, H19 promoter, and DLK1 differentially methylated regions showed the expected parent of origin methylation pattern (Plaia et al. 2006), suggesting a tight control of methylation imprints in 
Downloaded from genome.cshlp.org on April 26, 2023 - Published by Cold Spring Harbor Laboratory Press

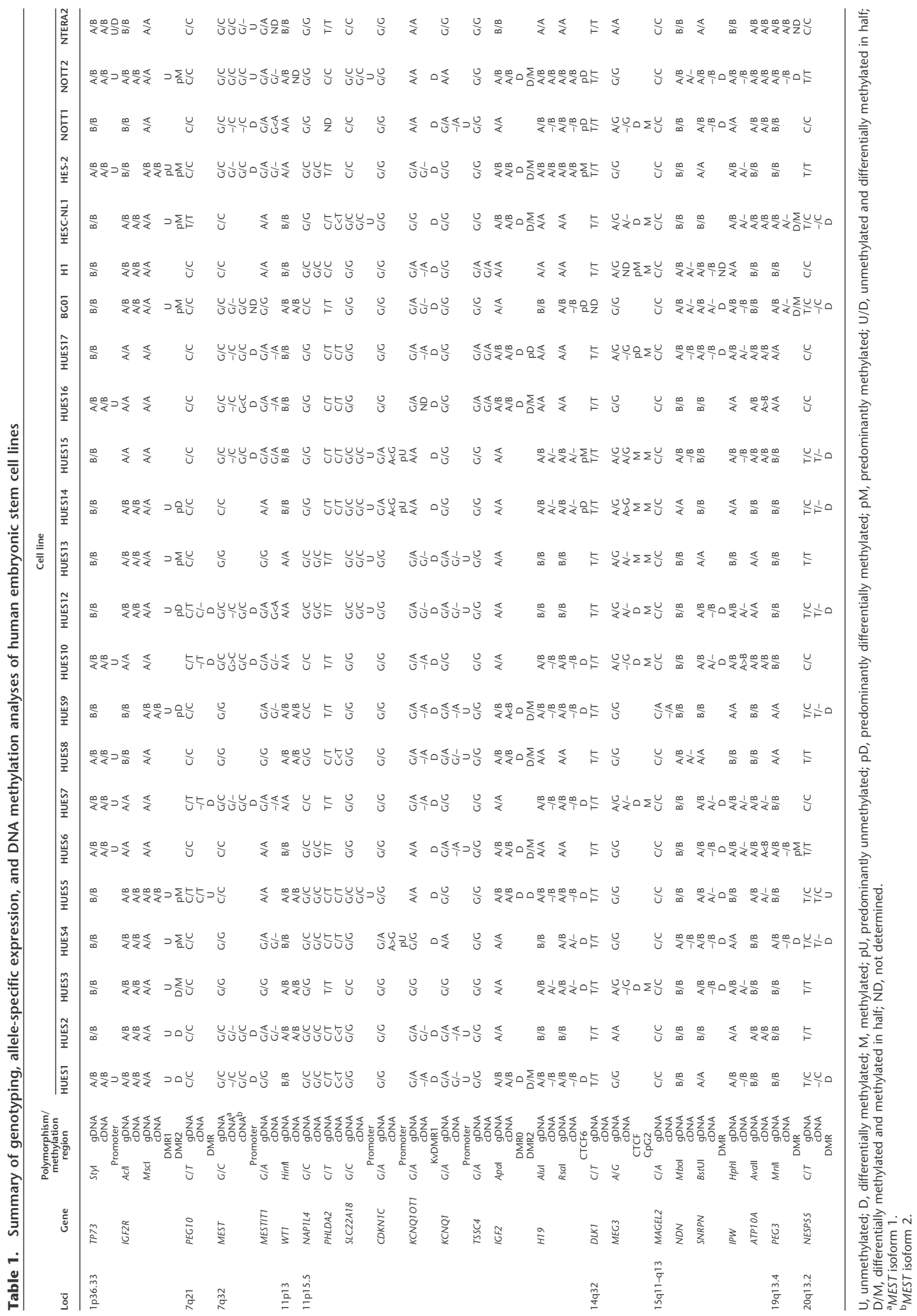


A

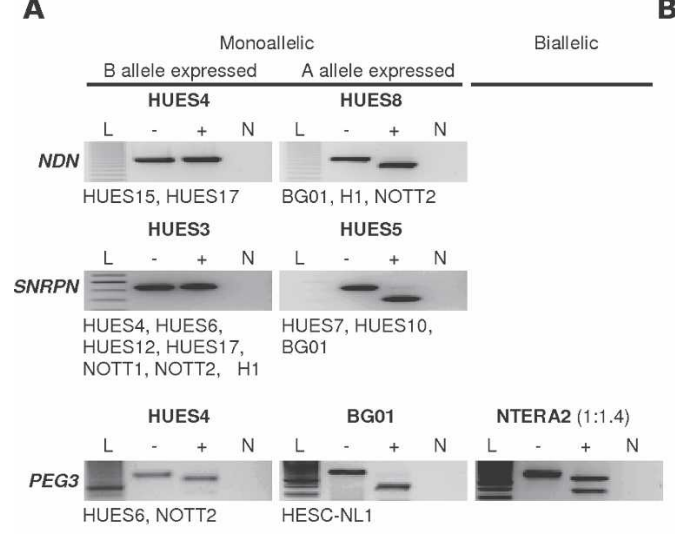

B

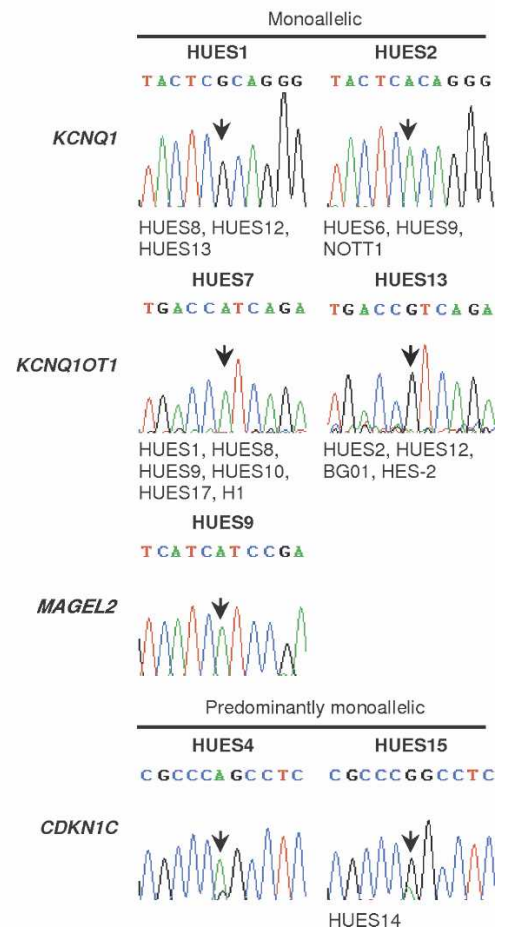

Figure 1. Genes monoallelically expressed in all informative cell lines. Allele-specific gene expression status was determined by $(A)$ RFLP where the " $\mathrm{A}$ " allele contains the restriction site and a band ratio of $<1: 3$ indicates biallelic expression (L, DNA ladder; - , undigested PCR product; +, digested PCR product; $\mathrm{N}$, no reverse transcriptase control) or (B) CDNA sequencing where arrows indicate polymorphic sites.

human embryonic stem cells. However, the allelic expression status was not investigated in these two studies. Data from the mouse embryo have suggested that some imprints are not fully established until the time of implantation (Szabo and Mann 1995; Rossant et al. 1998) and this has been corroborated in the human. Although only a few imprinted genes have been examined to date in human preimplantation embryos, SNRPN (Huntriss et al. 1998), MEST (previously known as PEG1) (Monk and Salpekar 2001), and IGF2 (Lighten et al. 1997) show monoallelic expression at this stage, whereas H19 (Salpekar et al. 2001) and XIST (Ray et al. 1997; Monk and Salpekar 2001) are only monoallelically expressed in postimplantation tissues (Morison et al. 2005). Thus we examined the methylation status of a range of imprinted gene regulatory regions in order to investigate the role of this epigenetic modification in regulating genomic imprints in hESC.

Some genes selected in the present study were chosen due to their known function having potential relevance to hESC properties or applications, including genes involved in cell proliferation and tumorigenesis (Hernandez et al. 2003; Holm et al. 2005). Others were of interest due to their known imprinting disruption in a range of disease conditions and thus their known susceptibility to unstable imprinting (DeBaun et al. 2003; Maher 2005; Morison et al. 2005; Robertson 2005). We were interested to examine 16 of the HUES hESC lines derived in Harvard University (Cowan et al. 2004). This cohort provided a large number of lines isolated and cultured in the same laboratory by similar procedures, thus were not confounded by the different culture protocols that are typical between lines derived in different laboratories (Allegrucci and Young 2007). We also examined the imprinting status of the NIH-registered lines, BG01 (Mitalipova et al.

2003), H1 (Thomson et al. 1998) and HES-2 (Reubinoff et al. 2000), HESC-NL1 (van de Stolpe et al. 2005), NOTT1, and NOTT2 (Burridge et al. 2006; Allegrucci et al. 2007). PCR-amplified DNA from each line was first genotyped for known imprinted gene human polymorphisms. Lines informative for imprinting studies, i.e., those determined to be heterozygous for the relevant polymorphism, were then subjected to RT-PCR and once again genotyped to determine the allelic expression status. The study revealed that, while some imprints appear to be stable in hESC lines, others are prone to disruption.

\section{Results}

A summary table of all results is presented as Table 1 .

\section{Genotyping to identify heterozygous individuals informative for imprinting analysis}

The genotyping data are presented in Supplemental Figure 1. No lines were heterozygous for a $\mathrm{C} / \mathrm{T}$ polymorphism in the $3^{\prime}$ UTR of DLK1 and so the imprinting status of this gene could not be determined.

\section{Allelic expression analysis}

In lines with informative imprinted gene polymorphisms, three categories of imprinted gene expression pattern were observed: genes monoallelic in all informative lines, genes biallelic in all informative lines, and genes with variable allelic expression between lines.

\section{Genes monoallelic in all informative lines}

Only seven genes of the 22 examined showed consistent monoallelic or predominant monoallelic expression in all informative lines (Fig. 1). NDN was monoallelically expressed in all seven heterozygous lines. One hundred percent of the 12 informative lines exhibited monoallelic expression of SNRPN. PEG3 was monoallelically expressed in 5/5 informative lines. Notably, however, PEG3 expression was from both alleles in the human embryonal carcinoma cell line, NTERA2 (Fig. 1A). KCNQ1 was found to be monoallelically expressed in $8 / 8$ informative lines and KCNQ1OT1 in all 12 heterozygous lines (Fig. 1B). Only a single line, HUES9, was heterozygous for a C/A polymorphism in MAGEL2 (previously known as NDNL1), exhibiting monoallelic expression. CDKNC1 was observed to be predominantly monoallelically expressed in 3/3 lines heterozygous for a G/A polymorphism.

\section{Genes biallelic in all informative lines}

TP73 (8/8 lines and NTERA2), WT1 (6/6), and SLC22A18 (7/7) were expressed in hESCs from both alleles in all informative hESC lines (Fig. 2A). In addition, IGF2R was examined using both AclI (12 informative lines) and MscI (three informative lines) 
A

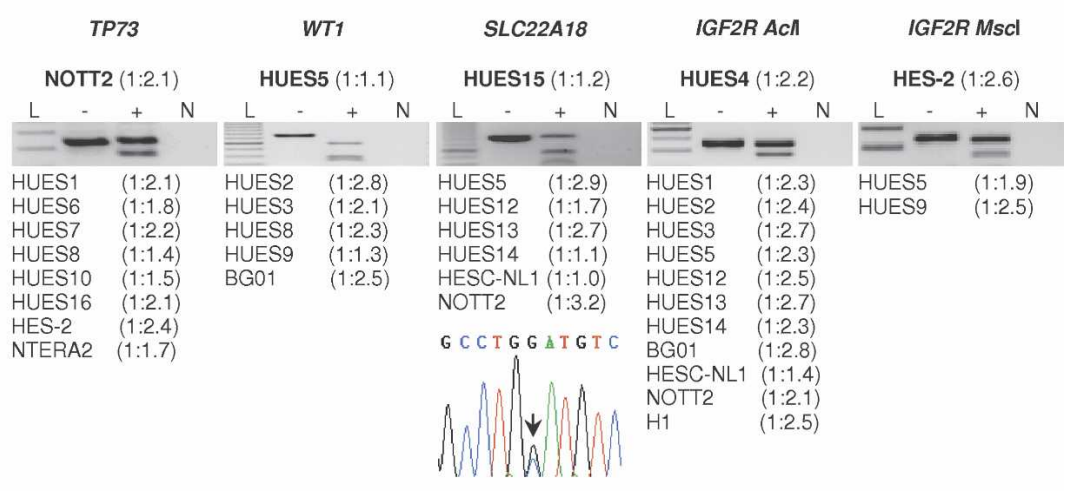

B

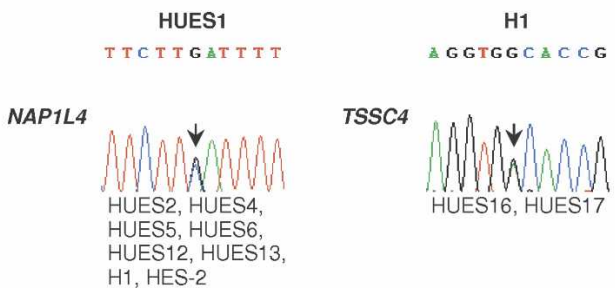

Figure 2. Genes biallelically expressed in all informative cell lines. (A) RFLP analysis of allele-specific expression where the " $\mathrm{A}$ " allele contains the restriction site and a band ratio of $<1: 3$ indicates biallelic expression (L, DNA ladder; -, undigested PCR product; +, digested PCR product; N, no reverse transcriptase control). The biallelic expression of $S L C 22 A 18$ was confirmed by sequencing. (B) Allele-specific expression status of the nonimprinted genes, NAP1L4 and TSSC4. Arrows indicate polymorphic sites.
Genes biallelic in most lines

As shown in Figure 4A, of 12 informative ATP10A (previously known as ATP10C) lines eight showed biallelic expression (allelic ratio 1:1.0-1:1.5), two showed predominant monoallelic expression (HUES6, 1:5.0; HUES16, 1:6.6), and two further lines showed expression from only a single allele (HUES5 and HUES7). Nine of 10 lines exhibited biallelic IGF2 expression, while HUES9 showed predominantly monoallelic expression (allelic ratio 1:3.7; Fig. 4A). MEST isoform 2 was expressed from both alleles in 10/12 lines, whereas it was predominantly monoallelically expressed in HUES16 and monoallelically expressed in NOTT1 and NTERA2 (Fig. 4B). Ten lines showed predominant PHLDA2 monoallelic expression in four cases and biallelic expression in six.

\section{Relationship of imprinting stability with chromosomal location and karyotype}

Since several of the imprinted genes we examined form part of imprinted gene clusters that are often coordinately regulated, we investigated a possible relationship between chromosomal location and imprint stability. Within the polymorphisms, exhibiting biallelic expression in all cases. HUES5 was heterozygous for both IGF2R polymorphisms. The nonimprinted genes, NAP1L4 and TSSC4, also showed biallelic expression, as expected (Fig. 2B).

\section{Genes with variable allelic expression between lines}

Ten genes showed variable allelic expression between lines (Figs. $3,4)$.

\section{Genes monoallelic in most lines}

11/12 informative hESC lines showed IPW expression from only one allele (Fig. 3A), but in HUES10 expression predominantly from a second allele was detected at a ratio of 1:4. Both AluI (11 informative lines) and RsaI (13 informative lines) polymorphisms were used to analyze H19 imprinting. Except for HES-2 and NOTT2, most lines examined monoallelically expressed $H 19$. The expression of HES-2 and NOTT2 from both H19 alleles was observed with $A l u \mathrm{I}$ and $R s a \mathrm{I}$ restriction fragment length polymorphisms (RFLPs) (Fig. 3A). MEST isoform 1 was monoallelically expressed in 10/12 hESC lines, but predominantly monoallelically expressed in HUES10 and biallelic in NOTT2 and NTERA2 (Fig. 3B). PEG10 was monoallelic in HUES7, HUES10, and HUES12 but biallelic in HUES5. In 8/10 lines MEG3 (previously known as GTL2) was monoallelic but predominant monoallelic expression was observed in HUES14 and expression in HUES15 was biallelic. No expression of MEG3 was observed in H1. NESP55 showed monoallelic expression in $8 / 9$ heterozygous lines but also biallelic expression in HUES5. Of 12 MESTIT1 informative lines, nine lines showed only monoallelic expression, HUES12 and NOTT1 showed predominant monoallelic expression, and HUES15 showed biallelic expression. Notably, no expression of MESTIT1 was detected in NTERA2. 11p15.5 Beckwith Wiedemann syndrome cluster, KCNQ1, KCNQ1OT1, and CDKN1C exhibited monoallelic expression in all lines and SLC22A18 was biallelic in all lines. The nonimprinted genes, NAP1L4 and TSSC4, were always biallelically expressed as expected. In contrast, IGF2 and PHLDA2 (biallelic in most) and $H 19$ (monoallelic in most) showed interline differences. In the 15q11.2-q13 Prader-Willi/Angelman syndrome region, IPW (mostly monoallelic) and ATP10A (mostly biallelic) showed variable allelic expression amidst a background of consistently monoallelic expression of NDN, MAGEL2, and SNRPN in all informative lines. Examination of the karyotype of the cell lines examined (Table 2) also failed to reveal a relationship between the chromosomal location of genes exhibiting variable imprinting and any chromosomes exhibiting abnormal karyotype.

\section{DNA methylation of selected DMRs and promoter regions}

Bisulfite sequencing analysis was then performed for selected genes identified as monoallelic, biallelic, or variably expressed above, to determine (1) whether overall DNA methylation in previously examined potential regulatory regions correlated with the typical expression status of each gene in human embryonic stem cells and (2) whether differences in DNA methylation were associated with interline variations in allelic expression. Direct sequencing was performed in order to give an overview of the mean methylation status of the cell lines examined and, in the case of MEST and NESP55, clonal bisulfite sequencing was performed to confirm interline differences.

\section{Methylation of genes typically monoallelic in hESC}

Within the genes that were monoallelic in all informative lines, differential methylation, hypermethylation, and hypomethyl-

\section{Genome Research}

www.genome.org 
A

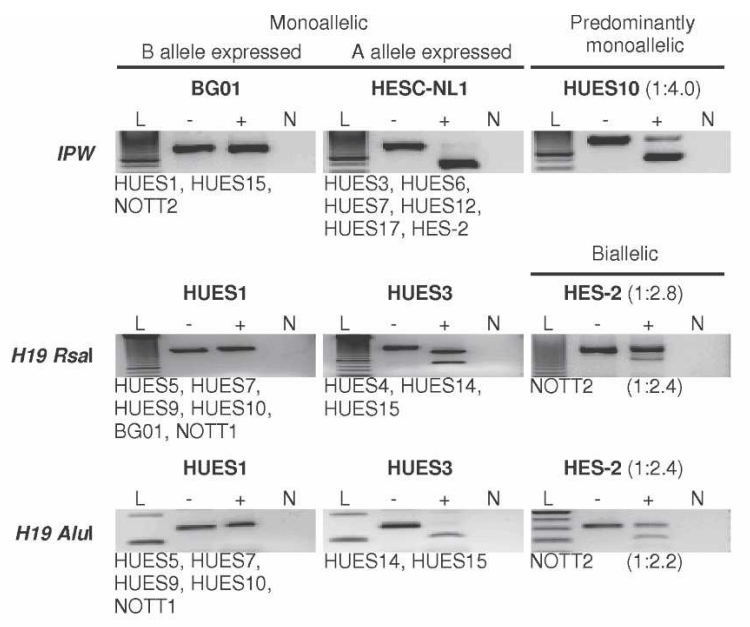

B

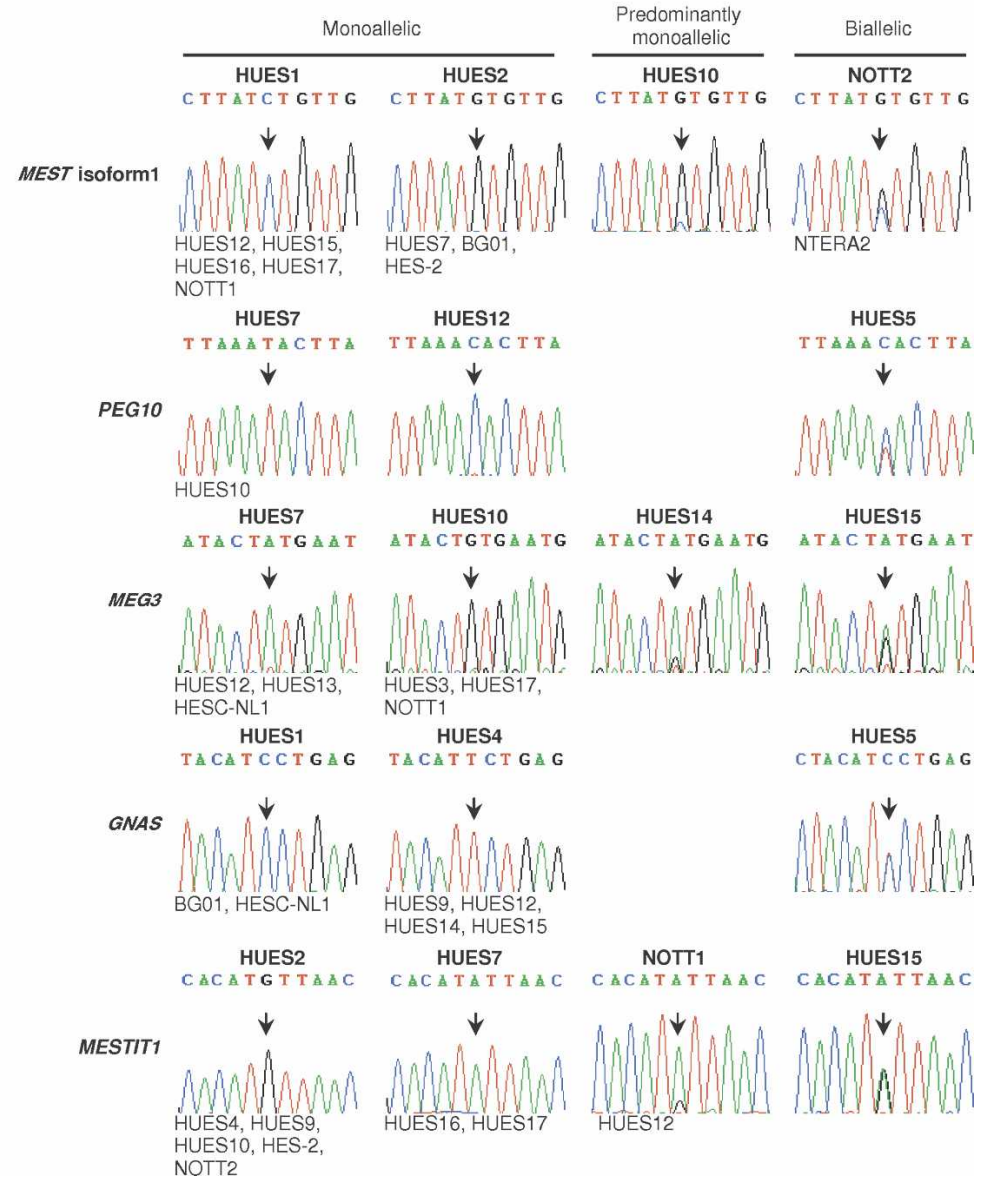

Figure 3. Genes indicating loss of imprinting in some hESC lines. Allele-specific gene expression status was determined by $(A)$ RFLP where the " $A$ " allele contains the restriction site and a band ratio of $<1: 3$ indicates biallelic expression (L, DNA ladder; - , undigested PCR product; + , digested PCR product; $N$, no reverse transcriptase control) or (B) CDNA sequencing where arrows indicate polymorphic sites.

ation were all observed scenarios. As shown in Figure 5, at the differentially methylated KvDMR1 imprinting control region (ICR) on chromosome 11p15.5, both methylated and unmethylated alleles were present across the $16 \mathrm{CpGs}$ examined, correlating with the monoallelic expression or predominant monoallelic expression observed in KCNQ1, KCNQ1OT1, and CDKN1C, but not the biallelic expression of SLC22A18. Of these four genes regulated by the KvDMR1 ICR in other human tissues (Monk et al. 2006), SLC22A18 is most distal. Hypomethylation was typical of the CpGs in the KCNQ1 and CDKN1C promoters, although differential methylation was evident between CDKN1C CpGs 15-24. The $S N R P N$ promoter was also differentially methylated in the 11 informative lines, correlating well with monoallelic expression. Most of the 12 CpGs examined in the PEG3 DMR were fully or differentially methylated in all five monoallelic lines.

We then examined the methylation status of genes that were monoallelic in most but not all lines (Fig. 5). In 23 CpGs surrounding the $H 19$ CTCF 6 binding region, the majority of CpGs demonstrated differential methylation, although in some lines several CpGs were fully methylated, even in the CTCF binding site. However, no obvious correlation with the variable allelic expression status between lines could be discerned. A similar scenario was observed in the MEG3 CTCF binding site, with lines exhibiting either fully methylated or hemimethylated CpGs that do not correlate with interline allelic expression differences. In addition, the MEG3 second $\mathrm{CpG}$ island (CpG2) was fully methylated in all lines.

The MEST promoter showed differential methylation in the range of MEST isoform 1 monoallelic lines and, interestingly, was unmethylated in NOTT2 and in NTERA2, both of which exhibited biallelic expression (Fig. 5). This was confirmed by sequencing of 10 PCR product clones. This loss of methylation in NOTT2 and NTERA2 is directly associated with loss of imprinting of MEST isoform 1. Furthermore, in eight hESC lines, the NESP55 DMR region comprised both methylated and unmethylated alleles at all of the $28 \mathrm{CpG}$ sites examined. However, direct sequencing indicated that all CpGs were unmethylated in HUES5 and this was confirmed by sequencing of 10 PCR product clones. This loss of methylation also correlated with the biallelic expression of NESP55 found only in HUES5. Differential methylation associated with monoallelic expression was observed typically at the PEG10 DMR, but, in HUES5 where this gene was biallelically expressed, no methylation was observed over 15 CpGs.

\section{Methylation of genes typically biallelic in hESC}

We examined DNA methylation in three genes found to be biallelic in all lines, TP73, IGF2R, and SLC22A18 (Fig. 5). Fifty CpG 
A

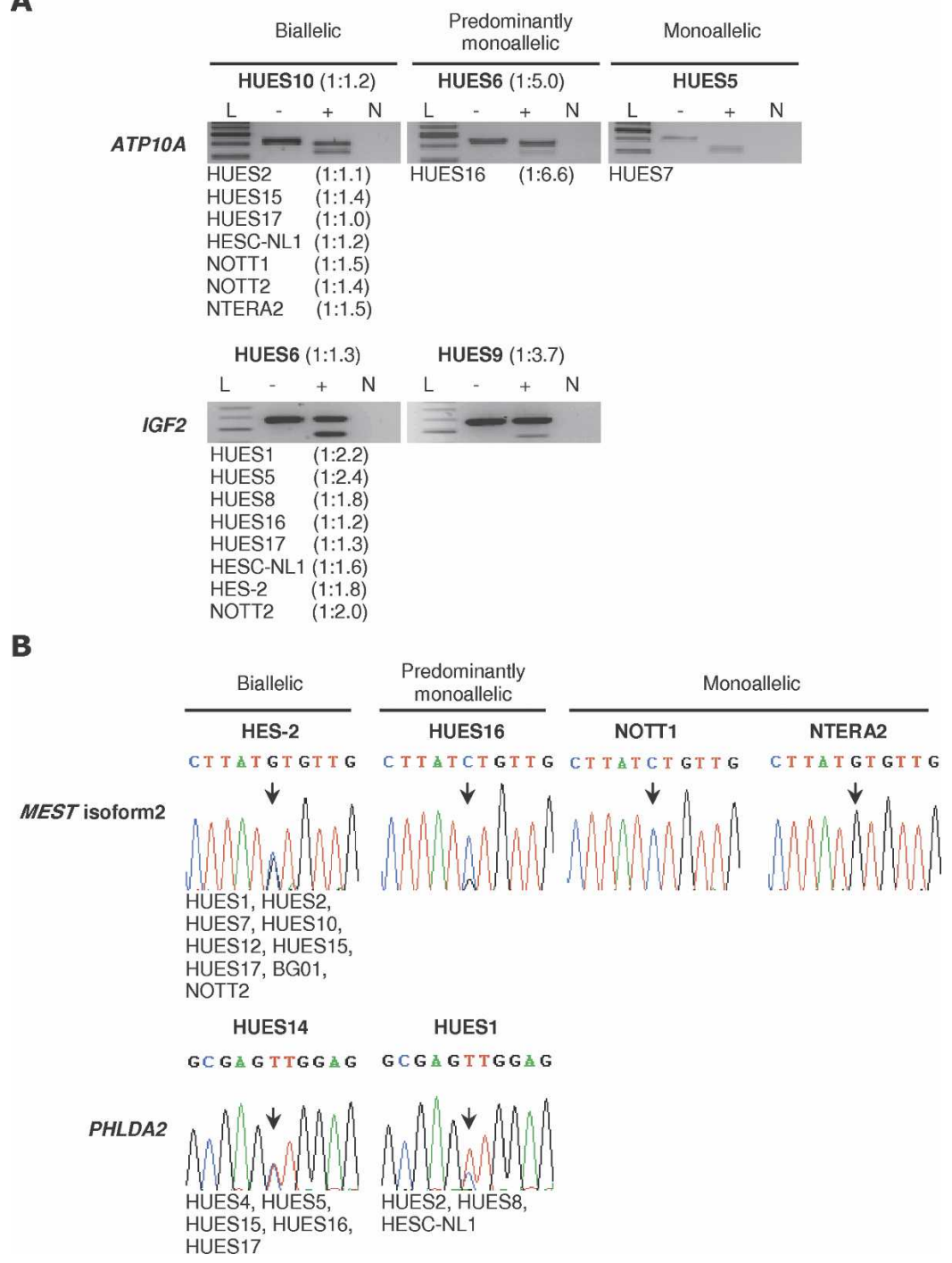

Figure 4. Genes indicating gain of imprinting in some hESC lines. Allele-specific gene expression status was determined by $(A)$ RFLP where the " $\mathrm{A}$ " allele contains the restriction site and a band ratio of $<1: 3$ indicates biallelic expression (L, DNA ladder; - , undigested PCR product; +, digested PCR product; $\mathrm{N}$, no reverse transcriptase control) or (B) CDNA sequencing where arrows indicate polymorphic sites.

sites in the TP73 promoter were mainly unmethylated in all lines, consistent with the biallelic expression observed. Thirtythree CpGs in the putative DMR1 region of IGF2R were also unmethylated in all lines examined, whereas the DMR2 was hypermethylated or differentially methylated in most cases. This methylation status is also consistent with the biallelic expression observed for IGF2R in $13 \mathrm{hESC}$ lines. The primarily unmethylated status of $32 \mathrm{CpG}$ sites in the SLC22A18 promoter once again correlates with the biallelic expression status of all lines examined.

Although the allelic expression status of lines varied at the IGF2 locus, no obvious correlation status with eight $\mathrm{CpG}$ dinucleotides in the DMR2 region with expression was noted. Whilst CpGs 6-8 were usually methylated, differential methylation was always observed at CpGs $1-5$ and in all of the six CpGs examined in DMR0 (Fig. 5). Similarly, despite differential CpG methylation at the MEST promoter in most lines that is inconsistent with the biallelic status of MEST isoform 2 in most lines (but consistent with the monoallelic expression typical of MEST isoform 1; see Fig. 3B), no correlation between the lines exhibiting monoallelic expression and the observed DNA methylation status was evident.

Since COBRA analysis of the NESP55 DMR, MEG3 CTCF, PEG10 DMR, and MEST promoter concurred with the bisulfite sequencing data obtained for each line (data not shown), we excluded the possibility of bisulfite sequencing errors such as clonality during the PCR amplification.

\section{Discussion}

Our results demonstrate that genomic imprinting can be vulnerable to disruption in a locus-specific manner in some human embryonic stem cell lines. This study represents analysis of $\sim 10 \%$ of the human embryonic stem cell lines known worldwide and concurs with the stability previously observed for KCNQ1OT1 (Rugg-Gunn et al. 2005), KCNQ1, MAGEL2 (Sun et al. 2006), SNRPN, and PEG3 (Adewumi et al. 2007). In marked contrast, however, $16 / 22$ of the hESC lines we examined exhibited a difference in allelic expression status in at least one imprinted gene from the status of the majority of lines examined at that locus. This includes the PEG10, NESP55, IGF2, and $I P W$ genes previously designated as invariant in preliminary studies (RuggGunn et al. 2005; Sun et al. 2006). HUES5 showed loss of imprinting at the PEG1O and NESP55 loci, but apparent gain of ATP1OA monoallelic expression in contrast to the biallelic expression of most hESC lines. The human embryonal carcinoma cell line, NTERA2, was the only other line examined to show disruption at three imprinted loci, whereas five other hESC lines showed disruption in two imprinted genes.

The imprinting variation between hESC lines showed no relationship with karyotypic aberrations, with chromosomal location, with gender, with culture conditions, or with typical parental expression status (i.e., maternal or paternal) in other human cell types. Thus the imprinting variations observed appear to be stochastic in susceptible loci. It is important to note that the hESCs examined in this study represent a snapshot in time and are not conclusive for a line or for differences in culture practice. This emphasizes the importance of regular characterization. Additionally, with over 200 lines worldwide, it may be that genes characterized as stably monoallelic or biallelic in this initial study are recharacterized as more lines are examined.

That nine different imprinted genes were affected in the 12/16 HUES-lines that showed imprint instability also raises the

\section{Genome Research}

www.genome.org 
Table 2. Cell lines used for this study

\begin{tabular}{|c|c|c|c|c|c|}
\hline & Passage & Karyotype & Passage method & Growth matrix & Reference \\
\hline \multicolumn{6}{|c|}{ Embryonic stem cell lines } \\
\hline HUES1 & 31 & $46, x x$ & Trypsin & MEFs & Cowan et al. 2004 \\
\hline HUES2 & 27 & $46, x X$ & Trypsin & MEFs & Cowan et al. 2004 \\
\hline HUES3 & 37 & $46, X Y$ & Trypsin & MEFs & Cowan et al. 2004 \\
\hline HUES4 & 26 & $46, X Y$ & Trypsin & MEFs & Cowan et al. 2004 \\
\hline HUES5 & 30 & $46, X X$,inv9 & Trypsin & MEFs & Cowan et al. 2004 \\
\hline HUES 6 & 35 & $46, x x$ & Trypsin & MEFs & Cowan et al. 2004 \\
\hline HUES7 & 26 & $46, X Y$ & Trypsin & MEFs & Cowan et al. 2004 \\
\hline HUES8 & 37 & $46, X Y$ & Trypsin & MEFs & Cowan et al. 2004 \\
\hline HUES9 & 30 & $46, X X$,inv 9 & Trypsin & MEFs & Cowan et al. 2004 \\
\hline HUES10 & 29 & $46, X Y$ & Trypsin & MEFs & Cowan et al. 2004 \\
\hline HUES12 & 28 & $46, x x$ & Trypsin & MEFs & Cowan et al. 2004 \\
\hline HUES13 & 32 & $46, X Y$ & Trypsin & MEFs & Cowan et al. 2004 \\
\hline HUES14 & 27 & $46, x x$ & Trypsin & MEFs & Cowan et al. 2004 \\
\hline HUES15 & 31 & $46, x X$ & Trypsin & MEFs & Cowan et al. 2004 \\
\hline HUES16 & 29 & $46, X Y$ & Trypsin & MEFs & Cowan et al. 2004 \\
\hline HUES17 & 35 & $46, X Y$ & Trypsin & MEFs & Cowan et al. 2004 \\
\hline BG01 & 45 & $46, X Y$ & Mechanical & MEFs & Mitalipova et al. 2003 \\
\hline $\mathrm{H} 1$ & 26 & $46, X Y$ & Trypsin & Matrigel & Thomson et al. 1998 \\
\hline HESC-NL1 & 22 & $46, X X$ & Mech+Disp & MEFs & van de Stolpe et al. 2005 \\
\hline HES-2 & 56 & $46, x x$ & Mech+Disp & MEFs & Reubinoff et al. 2000 \\
\hline NOTT1 & 25 & $46, x X$ & Trypsin & Matrigel & Burridge et al. 2006; Allegrucci et al. 2007 \\
\hline NOTT2 & 32 & $46, X Y$ & Trypsin & Matrigel & Burridge et al. 2006; Allegrucci et al. 2007 \\
\hline \multicolumn{6}{|c|}{ Embryonal carcinoma } \\
\hline NTERA2 & 70 & $46, X Y$ & Mechanical & MEFs & Andrews et al. 1984 \\
\hline
\end{tabular}

MEFs, mouse embryonic fibroblasts; Mech, mechanical passaging; Disp, dispase.

possibility that these errors were inherited from the originating embryo, since all of these lines were derived and cultured in the same way (Cowan et al. 2004) and were analyzed at similar passage number (p26-37). All of the HUES-lines were derived from frozen, grade 3-4 blastocysts supernumerary from fertility treatments (Cowan et al. 2004). Given several recent reports of increased incidence of imprinting errors in in vitro cultured animal embryos (Young et al. 2001; Mann et al. 2003, 2004; Fujimoto et al. 2006), children conceived through assisted reproduction technologies (DeBaun et al. 2003; Maher 2005; Robertson 2005), in superovulated human oocytes (Sato et al. 2007), and in the spermatozoa of oligospermic men (Marques et al. 2004), more studies on imprinting in the human embryo are now required to evaluate the biorisk for stem cell derivations. Imprinting variability was not restricted to the HUES-lines and thus cannot be attributed to the use of trypsin passaging on mouse embryonic fibroblast feeders that was unique to these lines (Cowan et al. 2004).

Previous studies of imprinting in hESCs identified monoallelic (or predominantly monoallelic) expression of all genes tested (Rugg-Gunn et al. 2005; Sun et al. 2006), except SLC22A18, which was frequently biallelic (Adewumi et al. 2007). Importantly, our current observations of biallelic expression of four genes (TP73, IGF2R, WT1, and SLC22A18) in 100\% of informative lines tested suggest that this may be the norm for several "imprinted" genes at this developmental stage. The biallelic expression of ATP1OA, IGF2, and MEST isoform 2 in the majority of lines analyzed also indicates that this may be the "normal" imprinting status for these genes in hESCs. This is in agreement with our study of imprinted genes in sheep blastocysts, where nine genes examined exhibited monoallelic expression only post-implantation (Thurston et al. 2008). A gene-specific, temporal imprinting pattern has also been suggested by the observation of both monoallelically and biallelically expressed imprinted genes in human (Lighten et al. 1997; Ray et al. 1997; Huntriss et al. 1998; Monk and Salpekar 2001; Salpekar et al.
2001), mouse (Szabo and Mann 1995; Rossant et al. 1998), and bovine (Ruddock et al. 2004) blastocysts. However, while it is tempting to speculate that the allelic expression status (i.e., monoallelic or biallelic) we ascertain for the majority of hESC lines tested represents the norm of the inner cell mass cells of the human blastocyst for each gene, in the absence of data of the allelic status for most genes in the human blastocyst, we cannot exclude the possibility that the majority of lines we have evaluated are in fact abnormal at a particular locus. Thus the biallelic expression of some "imprinted" genes in hESCs could indicate a tissue-specific pattern of imprinting, indicate that the process of imprinting is not yet complete at some loci, or indicate that virtually all lines show disrupted imprinting at these loci. Of interest is that mouse ES cell lines are usually derived not from the inner cell mass of the blastocysts (as in hESCs) but from the later, epiblast stage embryo, and this may explain why the usual expression status of the imprinted genes examined thus far in mESCs is fully monoallelic (Dean et al. 1998). For some genes, such as $I G F 2 R$, the lack of monoallelic expression or differential methylation in hESCs is consistent with the lack of imprinting reported in other human tissues, in contrast to the mouse (Barlow et al. 1991). No evidence of the polymorphic imprinting of $I G F 2 R$ observed previously in a minority of human placental samples (Monk et al. 2006) was noted in the 14 hESC lines examined.

The reasons why some imprinted genes should be more or less prone to disruption at a particular developmental stage are not yet understood. However, this phenomenon has been previously observed, for example Large Offspring Syndrome (LOS) induced by in vitro embryo culture or somatic cell nuclear transfer in sheep (Young et al. 2001, 2003) disrupts the IGF2R gene that is rarely affected in humans or mice (Gicquel et al. 2004). The disruption of IGF2, H19, and other $11 \mathrm{p} 15.5 /$ mouse distal chromosome 7 genes that is relatively more common in humans, rhesus monkeys, and mice (Dean et al. 1998; Humpherys et al. 2001; 
Kim et al.
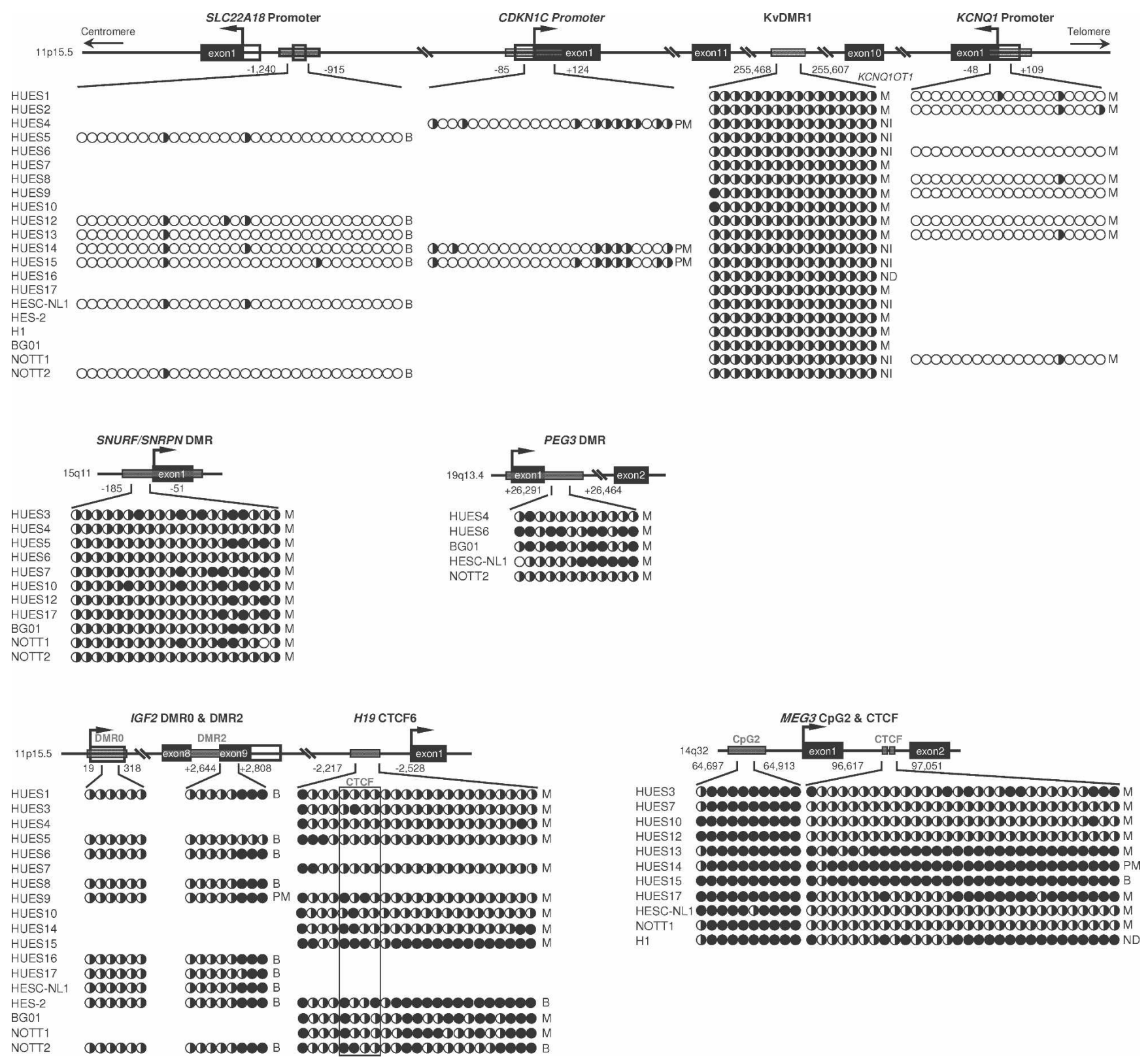

Figure 5. (Continued on next page)

Mann et al. 2003; Ogawa et al. 2003; Mann et al. 2004; Fujimoto et al. 2006) has not been observed in sheep. Since one possibility is the appropriation of different imprinting regulatory mechanisms between genes in the preimplantation embryo, we examined the status of a candidate epigenetic mechanism, $\mathrm{CpG}$ methylation. For several genes (KCNQ1, KCNQ1OT1, CDKN1C, SNRPN, MEST isoform 1, and NESP55), monoallelic expression in hESCs was associated with differential methylation of previously published differentially methylated regions (DMRs) and promoter regions, indicating a regulatory role for DNA methylation at these loci. Furthermore, biallelic expression was associated with hypomethylation in the putative IGF2R DMR1 and in the TP73 and SLC22A18 promoters. However, hypermethylation of MEG3 CpG2 was also associated with monoallelic expression, suggesting that DNA methylation does not regulate the monoal- lelic expression of at least some imprinted genes in hESCs, whereas it does play a role in more differentiated tissues. A similar discrepancy of DNA methylation at imprinted loci between the placenta and fetus has recently been reported by Monk et al. (2006). Notably, however, loss of imprinting at NESP55, MEST isoform 1, and PEG10 in individual hESC lines was directly associated with a loss of methylation relative to monoallelically expressed lines. Thus, locus-specific alterations in DNA methylation provide a candidate mechanism for further investigation of the causes of imprinting disruption in hESCs, perhaps via environmental availability of methyl groups (Steele et al. 2005), but other imprinting regulators such as histone modifications now require investigation.

As in the identification of any unstable feature identified in cultured hESC lines, it is likely that not all variations will have

\section{Genome Research www.genome.org}



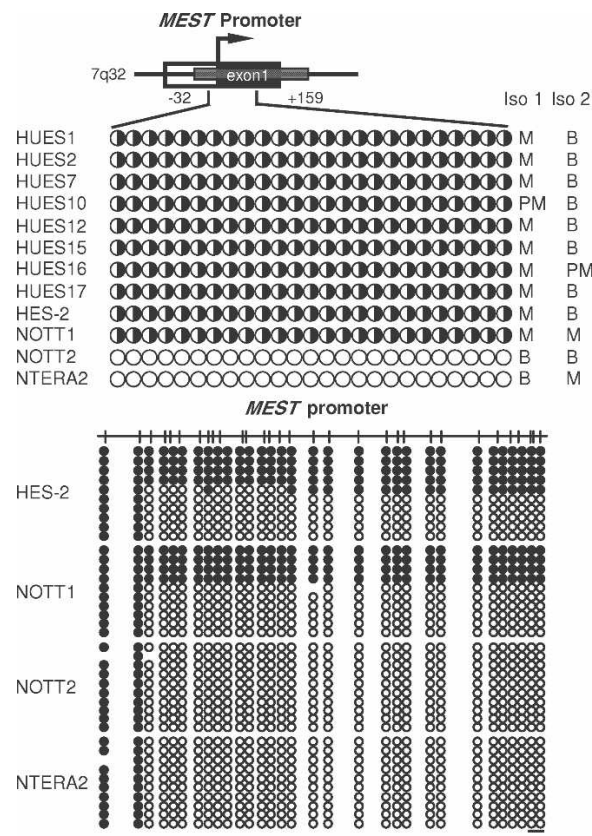

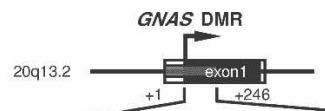

HUES1 \$010001000000000001000100000 M

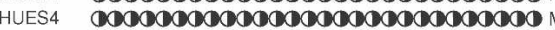

HUES5 0000000000000000000000000000 B

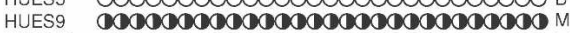

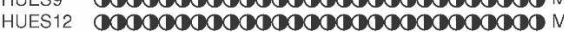

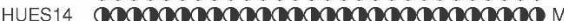

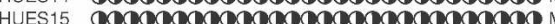

BGO1

HESC-NL1 $100000000000000000000000000 \mathrm{M}$

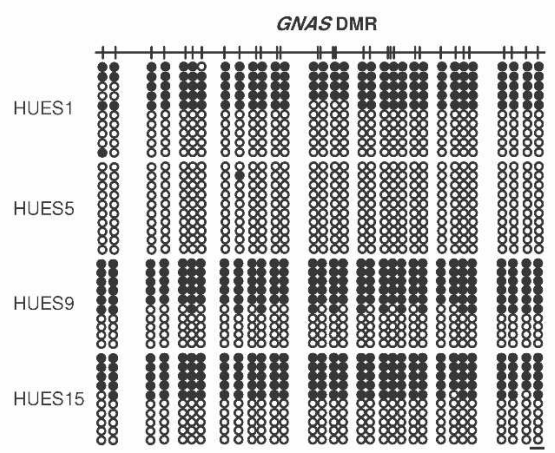

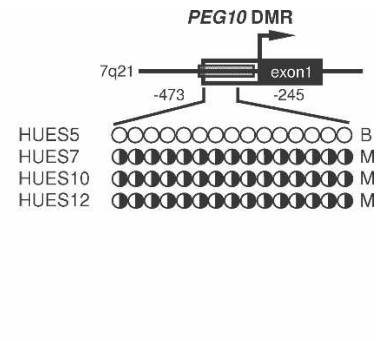

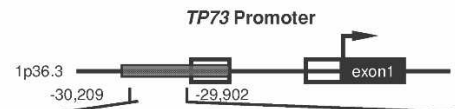

00000000000000000000000000000000000000000000000000 в 0000000000000000000000000000900000000000000000000 в

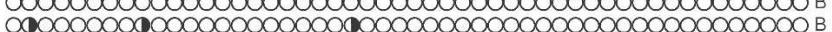
00000000000000000000000000000000000000000000000000 в В 00000000000000000000000000000000000000000000000000 B , 000000000000000000000000000000000000000000000000 B

$\begin{array}{ll}\text { NOTT2 } & \text { OODOOODO000000000000000000000000000000000000000000 B } \\ \text { NTERA2 } & 000000000000000000000000000000000000000000 \text { B }\end{array}$

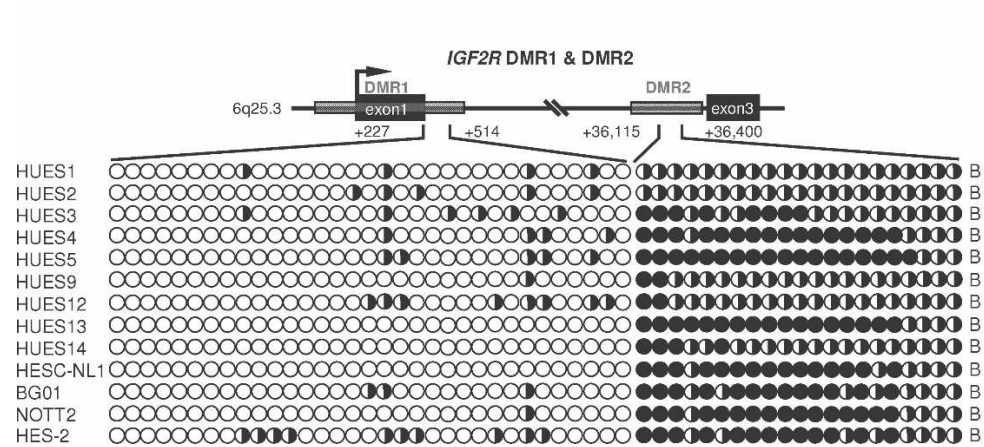

Figure 5. DNA methylation status of potential imprinting regulatory regions. Direct sequencing of bisulphate-treated DNA PCR products revealed the average DNA methylation status of individual $\mathrm{CpG}$ dinucleotides, represented by circles. Open circles, unmethylated; filled circles, methylated; halffilled/open circles, differentially methylated (or hemimethylated). Black boxes represent exons, white boxes represent UTRs, and gray boxes indicate $\mathrm{CpG}$ islands of each gene. Arrows indicate transcriptional start sites. Chromosomal locations of each gene are shown on left sides of diagrams. Numbers indicate the sequence position analyzed within each gene. For KCNQ1 promoter, CDKN1C promoter, SLC22A18 promoter, NESP55 DMR, MEST promoter, PEG10 promoter, H19 CTCF6, SNRPN DMR, PEG3 DMR, IGF2R DMRs, and TP73 promoter, the first and last CpGs are numbered relative to the transcriptional start site. For KvDMR1, numbering refers to accession no. AJ006345. For MEG3 CpG2 and CTCF, numbering refers to accession no. AL117190. For IGF2 DMR0, numbering refers to accession no. NM_001007139. For IGF2 DMR2, numbering refers to accession no. AC005809 and to the first nucleotide of exon 7. Clonal bisulfite sequencing is also shown for the MEST promoter and NESP55 DMR. Each row represents a unique clone of DNA from the hESC lines indicated. The horizontal bars represent $10 \mathrm{bp}$ of each gene analyzed. The corresponding allelic expression status of each line analyzed is also indicated; M, monoallelic; B, biallelic; PM, predominantly monoallelic; ND, not determined; NI, not informative; Iso 1, MEST isoform 1; Iso 2, MEST isoform 2.

any obvious consequence for utility of these cells in regenerative medicine or as an in vitro model for the human embryo. Given the known roles of these imprinted genes in cell proliferation and differentiation (http://www.mgu.har.mrc.ac.uk/research/ imprinting/function.html), as well as in tumorigenesis (Hernandez et al. 2003; Holm et al. 2005; Robertson 2005; Jelinic and Shaw 2007), routine screening of lines will be prudent. Whether some disrupted imprints indeed have phenotypic consequences 
for the lineage-specific differentiation and post-transplantation function of hESCs now needs to be established.

\section{Methods}

\section{Culture of hESCs}

Table 2 summarizes the characteristics and culture methods employed for the various hESC lines. Culture of the HUES-lines was as described in Cowan et al. (2004), of H1 was as described in Thomson et al. (1998), of BG01, NOTT1, and NOTT2 was as described (Burridge et al. 2006; Allegrucci et al. 2007), and of HES-2 and HESC-NL1 was as described (Reubinoff et al. 2000; van de Stolpe et al. 2005). NTERA2 was cultured as described (Andrews et al. 1984).

\section{Genotyping and allelic expression determination}

Genomic DNA was extracted from the hESC line and NTERA2 using the DNA extraction kit (Qiagen). PCR was performed in a $25 \mu \mathrm{L}$ reaction volume, with 0.625 Units of Hotstar Taq polymerase (Qiagen), $1 \times$ supplied reaction buffer, $0.5 \mu \mathrm{M}$ of each primer, 1.5-2.5 $\mathrm{mM}$ of $\mathrm{MgCl}_{2}, 0.25 \mathrm{mM}$ of dNTP (Invitrogen), and $50 \mathrm{ng}$ of each DNA template. The PCR cycling conditions were $95^{\circ} \mathrm{C}$ for $15 \mathrm{~min}$ followed by $35-40$ cycles $\left(95^{\circ} \mathrm{C}\right.$ for $1 \mathrm{~min}, \mathrm{X}^{\text {optimal }}{ }^{\circ} \mathrm{C}$ for $30 \mathrm{sec}, 72^{\circ} \mathrm{C}$ for $1 \mathrm{~min}$ ) and a final extension step at $72^{\circ} \mathrm{C}$ for $9 \mathrm{~min}$. All primers and optimal PCR conditions (including $\mathrm{X}^{\text {optimal }}{ }^{\circ} \mathrm{C}$ ) are described in Supplemental Table 1. Total RNA was extracted from each cell line using the RNeasy Mini kit (Qiagen), treating with DNase (Ambion) before cDNA synthesis; $0.5 \mu \mathrm{g}$ of total RNA was reverse-transcribed using the First-strand cDNA synthesis kit (Amersham) and the supplied pd(N)6 primer. To control for DNA contamination, a parallel reaction was carried out without reverse transcriptase. PCR was performed as described above, using $2 \mu \mathrm{L}$ of cDNA per reaction. Genotyping for known polymorphic regions in human imprinted genes was carried out either by RFLP (restriction fragment length polymorphism) analysis or by direct sequencing, according to the publications indicated in Supplemental Table 1. For RFLP, image analysis quantification of post-digestion band intensity was determined using a LAS-1000 camera (Fujifilm) and Aida (Raytek Scientific Ltd) software. Predominantly monoallelic expression was defined when the allelic ratio was $>1: 3$ (Cui et al. 1998).

\section{DNA methylation}

Five-hundred nanograms to $1 \mu \mathrm{g}$ of hESC DNA was bisulfitetreated followed by bisulfite PCR using the primers and optimal conditions shown in Supplemental Table 2. DNA was digested overnight at $37^{\circ} \mathrm{C}$ with either BamHI or EcoRI $(1 \mu \mathrm{L}$ of $10 \mathrm{U} / \mu \mathrm{L})$ with $1 \times$ supplied reaction buffer (Roche). The digest was then pipetted into a sterile screw-cap tube, incubated at $100^{\circ} \mathrm{C}$ for 5 min and then immediately placed on ice; $2.5 \mu \mathrm{L}$ of fresh $3 \mathrm{M}$ sodium hydroxide (Sigma) was added to each tube and incubated at $37^{\circ} \mathrm{C}$ for $20 \mathrm{~min}$. During the incubation period the bisulfite solution was prepared; $3.8 \mathrm{~g}$ of sodium bisulfite (Sigma) was mixed with $5 \mathrm{~mL}$ of RNase/DNase free water (Sigma) and $1.5 \mathrm{~mL}$ of $2 \mathrm{M}$ sodium hydroxide using a tube roller in a dark (foilcovered) tube. During this time, $110 \mathrm{mg}$ of hydroquinone (Sigma) was dissolved in $1 \mathrm{~mL}$ of water by heating at $50^{\circ} \mathrm{C}$ for 10 min. The dissolved hydroquinone was then added to the bisulfite solution, inverting the tube to mix. In total, $270 \mu \mathrm{L}$ of the freshly prepared bisulfite solution was then added to digested and denatured DNA, pipetting twice to mix. Following overlay of $200 \mu \mathrm{L}$ mineral oil (Sigma) each sample was incubated for $5 \mathrm{~h}$ at $55^{\circ} \mathrm{C}$ in the dark.
After the bisulfite incubation, $2 \mathrm{~mL}$ sterile tubes were prepared containing $600 \mu \mathrm{L}$ of RNase/DNase free water, $90 \mu \mathrm{L}$ of $3 \mathrm{M}$ sodium acetate (pH 5.2; Sigma), $2.5 \mu \mathrm{L}$ of Pellet Paint (Novagen), and the bisulphate-treated DNA (minus mineral oil); $900 \mu \mathrm{L}$ isopropanol (Sigma) was added and mixed by inversion, followed by centrifugation at 13,000 rpm for $20 \mathrm{~min}$. The pellet was washed with $800 \mu \mathrm{L}$ of $70 \%$ ethanol (Sigma), centrifuged for $5 \mathrm{~min}$ at $13,000 \mathrm{rpm}$ then the supernatant was removed with a pipette. The pellet was air-dried in a fume-hood on ice for $10 \mathrm{~min}$ and resuspended in $50 \mu \mathrm{L}$ of water (RNase/DNase free), followed by the addition of $5 \mu \mathrm{L}$ of fresh $3 \mathrm{M}$ sodium hydroxide to each sample and then incubating each at $37^{\circ} \mathrm{C}$ for $15 \mathrm{~min}$. DNA cleanup was performed using the Qiagen PCR purification kit according to the manufacturer's instructions.

Bisulfite primers (Sigma-Genosys) were designed using "MethPrimer" (Li and Dahiya 2002) or were previously published as described in Supplemental Table 2. To analyze the IGF2, PEG3, IGF2R, H19, and SNURF/SNRPN DMRs, in a final volume of $20 \mu \mathrm{L}$, bisulfite PCR comprised of AmpliTaq Gold ( $5 \mu \mathrm{L}$; Applied Biosystems), $5 \mu \mathrm{M}$ forward and reverse primers ( $2 \mu \mathrm{L}$; Sigma Genosys), RNase/DNase free water ( $7 \mu \mathrm{L}$; Sigma), and $2 \mu \mathrm{L}$ of bisulfite converted DNA. The PCR cycling conditions were $95^{\circ} \mathrm{C}$ for $5 \mathrm{~min}$ followed by 40 cycles $\left(95^{\circ} \mathrm{C}\right.$ for $30 \mathrm{sec}, \mathrm{X}^{\text {optimal }}{ }^{\circ} \mathrm{C}$ for $45 \mathrm{sec}, 72^{\circ} \mathrm{C}$ for $1 \mathrm{~min}$ ) and a final extension step at $72^{\circ} \mathrm{C}$ for $5 \mathrm{~min}$. For all other genes, bisulfite PCRs were performed as described in the Genotyping and Allelic Expression Determination section. Optimal annealing temperature $\left(\mathrm{X}^{\text {optimal }}{ }^{\circ} \mathrm{C}\right)$ was empirically determined for each primer set (Supplemental Table 2). PCR products were purified by using either PCR purification kit or QIAquick gel extraction kit (Qiagen) and then direct sequencing was performed to obtain an overview of DNA methylation. Bisulfite conversion of at least $95 \%$ was accepted.

\section{Cloning of bisulfite-treated PCR products}

PCR products were purified using either QIAquick gel extraction kit or PCR purification kit (Qiagen), cloned into TOPO vector (Invitrogen), and then subsequently transformed into TOP10 Escherichia coli (Invitrogen). Individual colonies were inoculated into LB medium containing Kanamycin (50 $\mu \mathrm{g} / \mathrm{mL}$; Sigma) and cultured overnight in a $37^{\circ} \mathrm{C}$ shaking incubator. Plasmids were extracted using the Qiaprep Spin Mini-prep kit (Qiagen). Ten insert-containing colonies (determined by the EcoRI digestion) were sequenced with the M13 forward primer by the DNA Sequencing Laboratory, University of Nottingham.

\section{Acknowledgments}

We thank Hannah Moore for assistance with the bisulfite sequencing method and Maria Munoz and Sonia Sebastian for technical assistance. This work was funded by BBSRC and by the University of Nottingham. K.-P.K. was supported by Korean Science and Engineering Foundation grant (no. F00008).

\section{References}

Adewumi, O., Aflatoonian, B., Ahrlund-Richter, L., Amit, M., Andrews, P.W., Beighton, G., Bello, P.A., Benvenisty, N., Berry, L.S., Bevan, S., et al. 2007. Characterization of human embryonic stem cell lines by the International Stem Cell Initiative. Nat. Biotechnol. 25: 803-816.

Allegrucci, C. and Young, L.E. 2007. Differences between human embryonic stem cell lines. Hum. Reprod. Update 13: 103-120.

Allegrucci, C., Denning, C., Priddle, H., and Young, L. 2004. Stem-cell consequences of embryo epigenetic defects. Lancet 364: 206-208.

Allegrucci, C., Wu, Y.Z., Thurston, A., Denning, C.N., Priddle, H., Mummery, C.L., Ward-van Oostwaard, D., Andrews, P.W., Stojkovic, M., Smith, N., et al. 2007. Restriction Landmark Genome Scanning 
identifies culture-induced DNA methylation instability in the human embryonic stem cell epigenome. Hum. Mol. Genet. 16: $1253-1268$.

Andrews, P.W., Damjanov, I., Simon, D., Banting, G.S., Carlin, C., Dracopoli, N.C., and Fogh, J. 1984. Pluripotent embryonal carcinoma clones derived from the human teratocarcinoma cell line Tera-2. Differentiation in vivo and in vitro. Lab. Invest. 50: 147-162.

Barlow, D.P., Stoger, R., Herrmann, B.G., Saito, K., and Schweifer, N. 1991. The mouse insulin-like growth factor type-2 receptor is imprinted and closely linked to the Tme locus. Nature 349: 84-87.

Bibikova, M., Chudin, E., Wu, B., Zhou, L., Garcia, E.W., Liu, Y., Shin, S., Plaia, T.W., Auerbach, J.M., Arking, D.E., et al. 2006. Human embryonic stem cells have a unique epigenetic signature. Genome Res. 16: 1075-1083.

Burridge, P.W., Anderson, D., Priddle, H., Barbadillo Munoz, M.D., Chamberlain, S., Allegrucci, C., Young, L.E., and Denning, C. 2006. Improved human embryonic stem cell embryoid body homogeneity and cardiomyocyte differentiation from a novel V-96 plate aggregation system highlights inter-line variability. Stem Cells 25: 929-938.

Cowan, C.A., Klimanskaya, I., McMahon, J., Atienza, J., Witmyer, J., Zucker, J.P., Wang, S., Morton, C.C., McMahon, A.P., Powers, D., et al. 2004. Derivation of embryonic stem-cell lines from human blastocysts. N. Engl. J. Med. 350: 1353-1356.

Cui, H., Horon, I.L., Ohlsson, R., Hamilton, S.R., and Feinberg, A.P. 1998. Loss of imprinting in normal tissue of colorectal cancer patients with microsatellite instability. Nat. Med. 4: 1276-1280.

Dean, W., Bowden, L., Aitchison, A., Klose, J., Moore, T., Meneses, J.J., Reik, W., and Feil, R. 1998. Altered imprinted gene methylation and expression in completely ES cell-derived mouse fetuses: Association with aberrant phenotypes. Development 125: 2273-2282.

DeBaun, M.R., Niemitz, E.L., and Feinberg, A.P. 2003. Association of in vitro fertilization with Beckwith-Wiedemann syndrome and epigenetic alterations of LIT1 and H19. Am. J. Hum. Genet. 72: $156-160$

Ferguson-Smith, A.C. and Surani, M.A. 2001. Imprinting and the epigenetic asymmetry between parental genomes. Science 293: $1086-1089$.

Fujimoto, A., Mitalipov, S.M., Kuo, H.C., and Wolf, D.P. 2006. Aberrant genomic imprinting in rhesus monkey embryonic stem cells. Stem Cells 24: 595-603.

Gicquel, C., Weiss, J., Amiel, J., Gaston, V., Le Bouc, Y., and Scott, C.D. 2004. Epigenetic abnormalities of the mannose-6-phosphate/IGF2 receptor gene are uncommon in human overgrowth syndromes. $J$. Med. Genet. 41: e4. doi: 10.1136/jmg.2003.010488.

Hernandez, L., Kozlov, S., Piras, G., and Stewart, C.L. 2003. Paternal and maternal genomes confer opposite effects on proliferation, cell-cycle length, senescence, and tumor formation. Proc. Natl. Acad. Sci. 100: $13344-13349$.

Holm, T.M., Jackson-Grusby, L., Brambrink, T., Yamada, Y., Rideout III, W.M., and Jaenisch, R. 2005. Global loss of imprinting leads to widespread tumorigenesis in adult mice. Cancer Cell 8: 275-285

Humpherys, D., Eggan, K., Akutsu, H., Hochedlinger, K., Rideout III, W.M., Biniszkiewicz, D., Yanagimachi, R., and Jaenisch, R. 2001. Epigenetic instability in ES cells and cloned mice. Science 293: 95-97.

Huntriss, J., Daniels, R., Bolton, V., and Monk, M. 1998. Imprinted expression of SNRPN in human preimplantation embryos. Am. J. Hum. Genet. 63: 1009-1014.

Jaenisch, R. and Bird, A. 2003. Epigenetic regulation of gene expression: How the genome integrates intrinsic and environmental signals. Nat Genet. 33 (Suppl.): 245-254.

Jelinic, P. and Shaw, P. 2007. Loss of imprinting and cancer. J. Pathol. 211: $261-268$

Lewis, A., Mitsuya, K., Umlauf, D., Smith, P., Dean, W., Walter, J., Higgins, M., Feil, R., and Reik, W. 2004. Imprinting on distal chromosome 7 in the placenta involves repressive histone methylation independent of DNA methylation. Nat. Genet. 36: $1291-1295$.

Li, L.C. and Dahiya, R. 2002. MethPrimer: Designing primers for methylation PCRs. Bioinformatics 18: 1427-1431.

Lighten, A.D., Hardy, K., Winston, R.M., and Moore, G.E. 1997. IGF2 is parentally imprinted in human preimplantation embryos. Nat. Genet. 15: 122-123.

Maher, E.R. 2005. Imprinting and assisted reproductive technology. Hum. Mol. Genet. 14: R133-R138.

Mann, M.R., Chung, Y.G., Nolen, L.D., Verona, R.I., Latham, K.E., and Bartolomei, M.S. 2003. Disruption of imprinted gene methylation and expression in cloned preimplantation stage mouse embryos. Biol. Reprod. 69: 902-914.

Mann, M.R., Lee, S.S., Doherty, A.S., Verona, R.I., Nolen, L.D., Schultz,
R.M., and Bartolomei, M.S. 2004. Selective loss of imprinting in the placenta following preimplantation development in culture. Development 131: 3727-3735.

Marques, C.J., Carvalho, F., Sousa, M., and Barros, A. 2004. Genomic imprinting in disruptive spermatogenesis. Lancet 363: 1700-1702.

Mitalipova, M., Calhoun, J., Shin, S., Wininger, D., Schulz, T., Noggle, S., Venable, A., Lyons, I., Robins, A., and Stice, S. 2003. Human embryonic stem cell lines derived from discarded embryos. Stem Cells 21: 521-526.

Monk, M. and Salpekar, A. 2001. Expression of imprinted genes in human preimplantation development. Mol. Cell. Endocrinol. 183: S35-S40.

Monk, D., Arnaud, P., Apostolidou, S., Hills, F.A., Kelsey, G., Stanier, P., Feil, R., and Moore, G.E. 2006. Limited evolutionary conservation of imprinting in the human placenta. Proc. Natl. Acad. Sci. 103: 6623-6628.

Morgan, H.D., Santos, F., Green, K., Dean, W., and Reik, W. 2005. Epigenetic reprogramming in mammals. Hum. Mol. Genet. 14: R47-R58.

Morison, I.M., Ramsay, J.P., and Spencer, H.G. 2005. A census of mammalian imprinting. Trends Genet. 21: 457-465.

Ogawa, H., Ono, Y., Shimozawa, N., Sotomaru, Y., Katsuzawa, Y., Hiura, H., Ito, M., and Kono, T. 2003. Disruption of imprinting in cloned mouse fetuses from embryonic stem cells. Reproduction 126: $549-557$.

Plaia, T.W., Josephson, R., Liu, Y., Zeng, X., Ording, C., Toumadje, A., Brimble, S.N., Sherrer, E.S., Uhl, E.W., Freed, W.J., et al. 2006. Characterization of a new NIH-registered variant human embryonic stem cell line, BG01V: A tool for human embryonic stem cell research. Stem Cells 24: 531-546.

Ray, P.F., Winston, R.M., and Handyside, A.H. 1997. XIST expression from the maternal $\mathrm{X}$ chromosome in human male preimplantation embryos at the blastocyst stage. Hum. Mol. Genet. 6: 1323-1327.

Reubinoff, B.E., Pera, M.F., Fong, C.Y., Trounson, A., and Bongso, A. 2000. Embryonic stem cell lines from human blastocysts: Somatic differentiation in vitro. Nat. Biotechnol. 18: 399-404.

Robertson, K.D. 2005. DNA methylation and human disease. Nat. Rev. Genet. 6: 597-610.

Rossant, J., Guillemot, F. Tanaka, M., Latham, K., Gertenstein, M., and Nagy, A. 1998. Mash2 is expressed in oogenesis and preimplantation development but is not required for blastocyst formation. Mech. Dev. 73: $183-191$.

Ruddock, N.T., Wilson, K.J., Cooney, M.A., Korfiatis, N.A., Tecirlioglu, R.T., and French, A.J. 2004. Analysis of imprinted messenger RNA expression during bovine preimplantation development. Biol. Reprod. 70: $1131-1135$.

Rugg-Gunn, P.J., Ferguson-Smith, A.C., and Pedersen, R.A. 2005. Epigenetic status of human embryonic stem cells. Nat. Genet. 37: $585-587$.

Salpekar, A., Huntriss, J., Bolton, V., and Monk, M. 2001. The use of amplified cDNA to investigate the expression of seven imprinted genes in human oocytes and preimplantation embryos. Mol. Hum. Reprod. 7: 839-844.

Sato, A., Otsu, E., Negishi, H., Utsunomiya, T., and Arima, T. 2007. Aberrant DNA methylation of imprinted loci in superovulated oocytes. Hum. Reprod. 22: 26-35.

Steele, W., Allegrucci, C., Singh, R., Lucas, E., Priddle, H., Denning, C. Sinclair, K., and Young, L. 2005. Human embryonic stem cell methyl cycle enzyme expression: Modelling epigenetic programming in assisted reproduction? Reprod. Biomed. Online 10: 755-766.

Sun, B.W., Yang, A.C., Feng, Y., Sun, Y.J., Zhu, Y., Zhang, Y., Jiang, H., Li, C.L., Gao, F.R., Zhang, Z.H., et al. 2006. Temporal and parental-specific expression of imprinted genes in a newly derived Chinese human embryonic stem cell line and embryoid bodies. Hum. Mol. Genet. 15: 65-75.

Szabo, P.E. and Mann, J.R. 1995. Allele-specific expression and total expression levels of imprinted genes during early mouse development: Implications for imprinting mechanisms. Genes \& Dev. 9: $3097-3108$

Thomson, J.A., Itskovitz-Eldor, J., Shapiro, S.S., Waknitz, M.A., Swiergiel, J.J., Marshall, V.S., and Jones, J.M. 1998. Embryonic stem cell lines derived from human blastocysts. Science 282: 1145-1147.

Thurston, A., Taylor, J.E., Gardner, J.O., Sinclair, K.D., and Young, L.E. 2008. Monoallelic expression of nine imprinted genes in the sheep embryo occurs after the blastocyst stage. Reproduction (in press).

Umlauf, D., Goto, Y., Cao, R., Cerqueira, F., Wagschal, A., Zhang, Y., and Feil, R. 2004. Imprinting along the Kcnq1 domain on mouse chromosome 7 involves repressive histone methylation and recruitment of Polycomb group complexes. Nat. Genet. 36: $1296-1300$.

van de Stolpe, A., van den Brink, S., van Rooijen, M., Ward-van 


\section{Kim et al.}

Oostwaard, D., van Inzen, W., Slaper-Cortenbach, I., Fauser, B., van den Hout, N., Weima, S., Passier, R., et al. 2005. Human embryonic stem cells: Towards therapies for cardiac disease. Derivation of a Dutch human embryonic stem cell line. Reprod. Biomed. Online 11: $476-485$.

Young, L.E., Fernandes, K., McEvoy, T.G., Butterwith, S.C., Gutierrez C.G., Carolan, C., Broadbent, P.J., Robinson, J.J., Wilmut, I., and Sinclair, K.D. 2001. Epigenetic change in IGF2R is associated with fetal overgrowth after sheep embryo culture. Nat. Genet.
27: $153-154$.

Young, L.E., Schnieke, A.E., McCreath, K.J., Wieckowski, S., Konfortova, G., Fernandes, K., Ptak, G., Kind, A.J., Wilmut, I., Loi, P., et al. 2003. Conservation of IGF2-H19 and IGF2R imprinting in sheep: Effects of somatic cell nuclear transfer. Mech. Dev. 120: 1433-1442.

Received April 13, 2007; accepted in revised form September 6, 2007. 


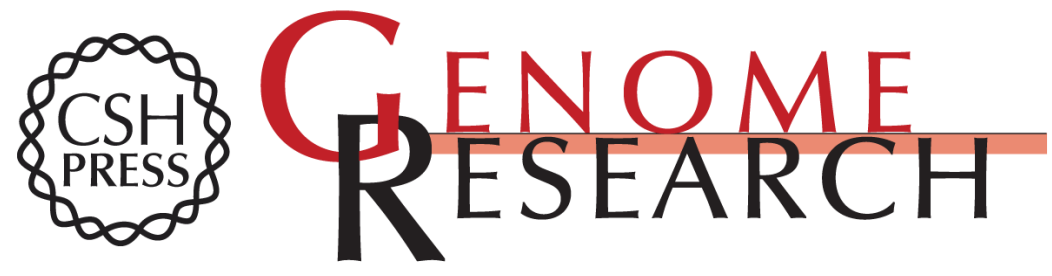

\section{Gene-specific vulnerability to imprinting variability in human embryonic stem cell lines}

Kee-Pyo Kim, Alexandra Thurston, Christine Mummery, et al.

Genome Res. 2007 17: 1731-1742 originally published online November 7, 2007

Access the most recent version at doi:10.1101/gr.6609207

Supplemental Material

References

License

Email Alerting Service
http://genome.cshlp.org/content/suppl/2007/11/08/gr.6609207.DC1

This article cites 51 articles, 11 of which can be accessed free at: http://genome.cshlp.org/content/17/12/1731.full.html\#ref-list-1

Receive free email alerts when new articles cite this article - sign up in the box at the top right corner of the article or click here.

\section{Affordable, Accurate Sequencing.}

